\title{
Phenomena and Factors of Port Disturbances by Long-period Waves at Kumaishi Fishing Port
}

\author{
Naoya ABESHIMA*, Kiyoshi AMAGAI**, Nobuo KIMURA**, \\ Shigeyoshi KODAMA***, and Hiroki ISHIMURA****
}

\begin{abstract}
At many ports throughout $J A P A N$, port disturbances caused by long-period oscillations are currently posing problems at many harbors and fishing ports but many questions about the mechanism of port disturbances are still remained.

In the present study, phenomena were analyzed by field observations and factors were analyzed numerically to clarify the mechanism of the port disturbance generation accompanying the advance of long-period waves into ports.

The results are as follows;

(1) The port disturbances at Kumaishi Fishing Port could be attributed to resonances between the natural periods of this port in Modes 1 through 3 and the long-period components of incoming waves.

(2) The results of observations and numerical analyses show, if a port has a natural beach and water passage, the resonance phenomenon reduces the amplitude amplification factor.
\end{abstract}

Key words: Oceanographic phenomena, Long-period oscillation, Long-period waves, Natural period,

Natural resonant mode

\section{Introduction}

Port disturbances by long-period oscillations are currently posing problems on vessel mooring and cargo handling at many harbors and fishing ports ${ }^{(1)(2)(3)}$. Even at Kumaishi Fishing Port located in the northern part of Oshima Peninsula, Hokkaido, port disturbances are caused by long-period oscillations, so vessel mooring and cargo handling incidents are becoming problems.

The plans of conventional fishing port are based on the wind wave data (short-period waves), therefore, the rate of effective working days for such a plan differs largely from that of what users predict by their visual and motion's sensations from waves and ship's motions. Long-period oscillations are thought to generate port disturbances because the long-period components contained in incoming waves are synchronized with the natural periods of ports.

In our previous report ${ }^{(4)}$ the authors analyzed the incoming waves along the coast of Hokkaido to determine the long-period components and to clarify the components always contained in the long-period wave energy of about $1.0 \%$ but many questions about them are still remained.

* Student Member : Doctoral Course, Graduate School of Fisheries Sciences of Hokkaido University.

(3-1-1 Minato-cho, Hakodate, Hokkaido 041-8611 JAPAN)

** Member : Graduate School of Fisheries Sciences of Hokkaido University.

(3-1-1 Minato-cho, Hakodate, Hokkaido 041-8611 JAPAN)

*** Non-Member : Fisheries Division, Agriculture and Fisheries Departmemt, Hokkaido Regional Development Bureau.

(Nishi2-chome, Kita 8-jo Kita-ku, Sapporo, Hokkaido 060-8511 JAPAN)

**** Non-Member : Esashi Port Construction Office, Hakodate Development and Construction Department, Hokkaido Regional Development Bureau.

(159 Ubagami-cho, Esashi-cho, Hiyama-gun, Hokkaido 043-0041 JAPAN) 
The present study was conducted at Kumaishi Fishing Port to clarify the mechanism of port disturbances and the followings are considered:

(1)Analyzing phenomena of port disturbances by field observations; and,

(2) Analyzing factors of port disturbances by numerical analyses.

\section{Analysis of Port Disturbance Phenomena by Field Observation}

\subsection{Disasters Caused by Port Disturbances}

Figure 1 shows the location of Kumaishi Fishing Port, which is analyzed in the present study. Kumaishi Fishing Port is a third-class port that serves as a refuge port in the event of storms. The port mainly serves the cuttlefish fishing industry in summer and the walleye pollack fishing industry in winter. The quay walls deep inside the port are used for preparations. Fishing vessels of the 5GT class are moored longitudinally and those of the 9GT class are moored in a parallel line.

Table 1 lists the disasters occurred at Kumaishi Fishing Port from 1995 to 2001, and Fig. 2 shows the locations of these accidents. The data show fishing vessels are damaged approximately one to four times in a year and are forced to take refuges in other ports. The accidents tend to occur mostly at (4), deep inside the port. Figure 3 shows the weather chart at the time of the disaster. As the figure shows, disaster tend to occur when a low-pressure area of typhoon passes through the Japan Sea.

As introduced above, Kumaishi Fishing Port does not act as a refuge port so it cannot protect moored vessels from being stricken by port disturbances Therefore, an understanding of the mechanism of the port disturbance generation and the possible measures concerned with port disturbances is urgently necessary.

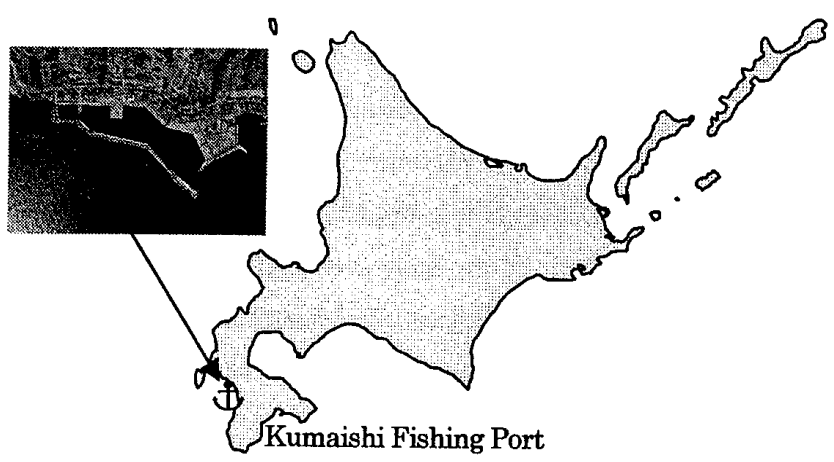

Fig. 1 Location of Kumaishi Fishing Port

Table 1 Actual results of accidents

\begin{tabular}{|c|c|c|c|c|c|}
\hline $\begin{array}{c}\text { Date } \\
\text { (year/month/day) }\end{array}$ & $\begin{array}{l}\text { Atmospheric } \\
\text { phenomena }\end{array}$ & $\begin{array}{l}\text { Location of } \\
\text { accidents }\end{array}$ & $\begin{array}{l}\text { Ship's tonnage } \\
\text { (GT) }\end{array}$ & $\begin{array}{c}\text { Number of } \\
\text { sheltering ships }\end{array}$ & Name of shelters \\
\hline $1995 / 11 / 8$ & cyclone & & & 15 & Esashi \\
\hline $1995 / 11 / 9$ & cyclone & (4) & $4.90,4.59,4.91,7: 40$ & & \\
\hline $1996 / 1 / 4$ & cyclone & (1) & 19.90 & & \\
\hline $1996 / 3 / 31$ & cyclone & (4) & $1.92,2.37$ & & \\
\hline $1996 / 8 / 15$ & typhoon -12 & & & 15 & Esashi \\
\hline $1996 / 11 / 6$ & cyclone & (4) & 4.91 & & \\
\hline $1996 / 11 / 16$ & cyclone & (4) & 7.40 & & \\
\hline $1997 / 2 / 17$ & cyclone & (4) & $4.50,3.00$ & & \\
\hline \multirow{2}{*}{$1997 / 8 / 5$} & cyclone & (1) & 9.89 & & \\
\hline & cyclone & (4) & $4.90,2.16,1.95$ & & \\
\hline $1997 / 8 / 8$ & typhoon-11 & & & 14 & Esashi \\
\hline $1998 / 3 / 15$ & cyclone & (4) & $7.40,2.03$ & & \\
\hline 1998/9/16 & typhoon -5 & & & 14 & Esashi \\
\hline $1998 / 10 / 17$ & typhoon-10 & & & 14 & Esashi \\
\hline $1999 / 9 / 24$ & typhoon-18 & & & 16 & Esashi,Otobe \\
\hline $1999 / 10 / 2$ & cyclone & & & 10 & Esashi,Otobe \\
\hline $1999 / 12 / 9$ & cyclone & (3) & 9.95 & & \\
\hline $2000 / 1 / 7$ & cyclone & (3) & $9.70,9.93$ & & \\
\hline $2000 / 1 / 8$ & cyclone & & & 5 & Sekinai \\
\hline $2000 / 2 / 1$ & cyclone & & & 6 & Sekinai \\
\hline $2000 / 7 / 7$ & typhoon -3 & & & 12 & Esashi,Otobe,Sekinai \\
\hline $2001 / 8 / 21$ & typhoon-11 & & & 10 & Esashi, Sekinai \\
\hline $2001 / 9 / 7$ & typhoon-15 & & & 18 & Sekinai \\
\hline $2001 / 12 / 15$ & cyclone & (1) & 9.89 & & \\
\hline $2001 / 12 / 30$ & cyclone & (3) & 9.93 & & \\
\hline
\end{tabular}




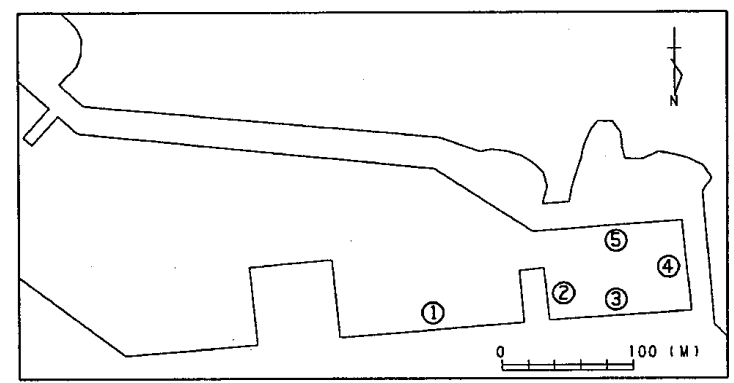

Fig. 2 Generating area of accidents

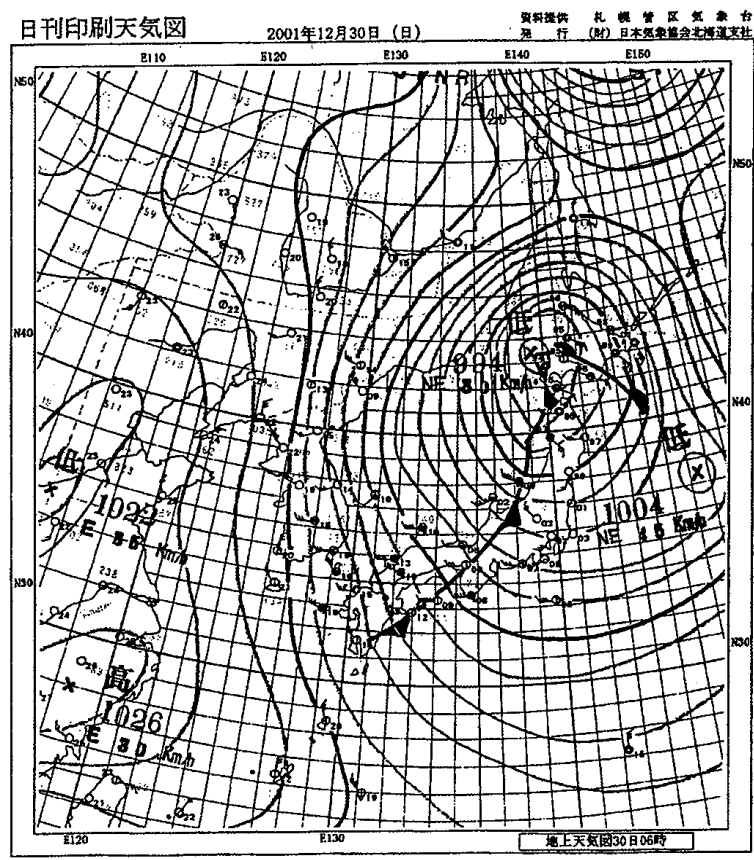

Fig. 3 Weather chart (2001/12/30)

\subsection{Outline of Field Observation}

Field wave observations were performed to confirm phenomena of port disturbances. The observation specifications are listed in Table 2, and the observation points are shown in Fig. 4. The field observations were performed outside the port (ST.1, water depth: $19.5 \mathrm{~m}$ ) and inside the port (ST.2, water depth: $3.5 \mathrm{~m}$ ) from January to February 2002 and from November 2002 to March 2003. Wave measurements were carried out with the sampling intervals of DT $=0.5 \mathrm{sec}$ for 20 minutes by an ultrasonic-type wave gage and an electromagnetic current meter (DL-2 made by Kyowa Shoko). The field observations were conducted by Esashi Port Construction Office, Hokkaido Regional Development Bureau.

Figure 5 shows the profile of Kumaishi Fishing Port during the field observation periods. The port had a natural beach and water passage (width: $\mathrm{W}=3.5 \mathrm{~m}$, water depth: $2.5 \mathrm{~m}$ as shown in Fig. 6) in from November

Table 2 Summary of observations

\begin{tabular}{|c|c|c|c|c|c|}
\hline Port name & Station No. & $\begin{array}{c}\text { Depth } \\
(\mathrm{m})\end{array}$ & $\begin{array}{l}\text { Observation } \\
\text { mode }\end{array}$ & Observation period & Case No. \\
\hline \multirow{3}{*}{ Kumaishi } & ST. 1 & 19.5 & 20min/hour & $2002.1 / 11 \sim 2002.2 / 14$ & Case 1 \\
\cline { 5 - 7 } & ST.2 & 3.5 & DT=0.5sec & $2002.11 / 21 \sim 2003.3 / 7$ & Case 2 \\
\hline
\end{tabular}

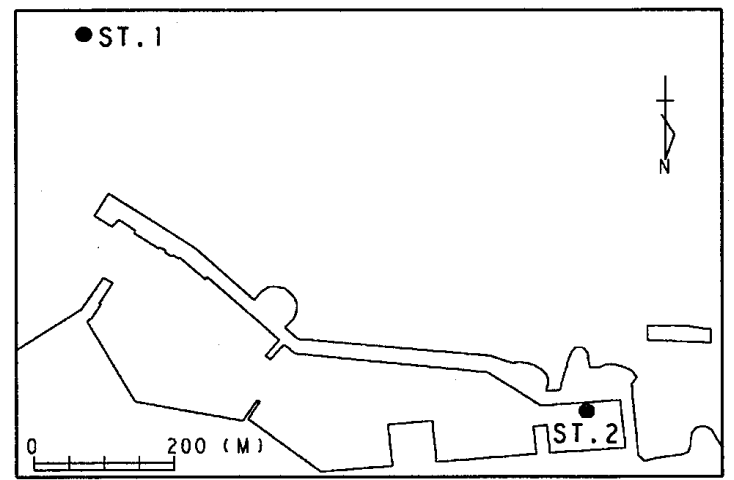

Fig. 4 Observational points

(1) natural beach
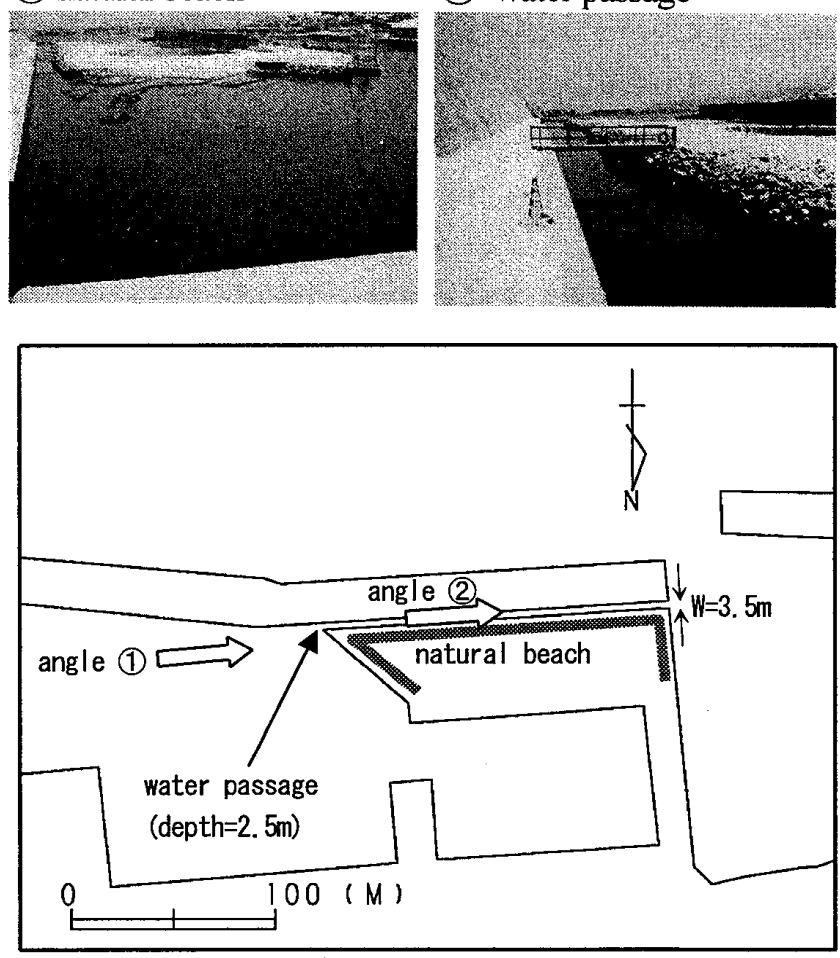

Fig. 6 Construction area

2002 to March 2003 because extension works were underway inside the port. The port disaster data obtained before the extension works were evaluated as Case 1 and those obtained during the extension works were evaluated as Case 2. The authors analyzed the factors contributing to port disturbances, as well as the influences of discrepancies at the port boundary, by comparing Cases 1 and 2 . 


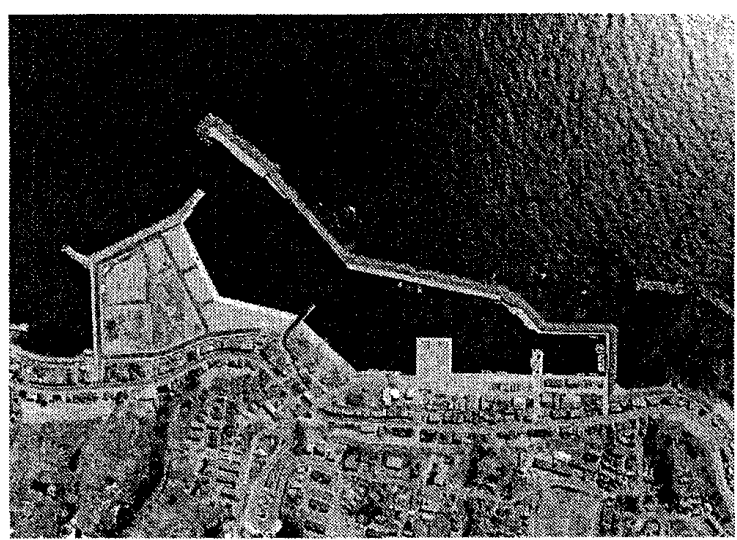

Case 1

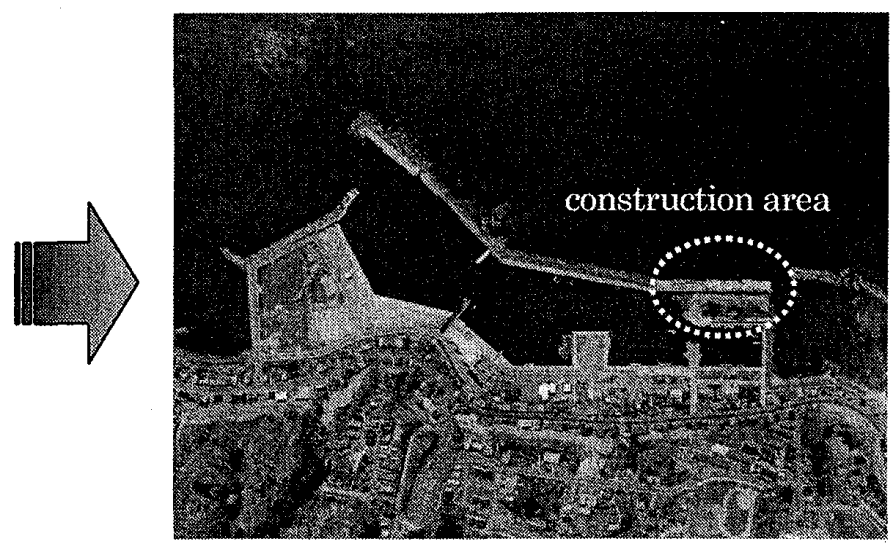

Case 2

Fig. 5 Construction of Kumaishi Fishing Port

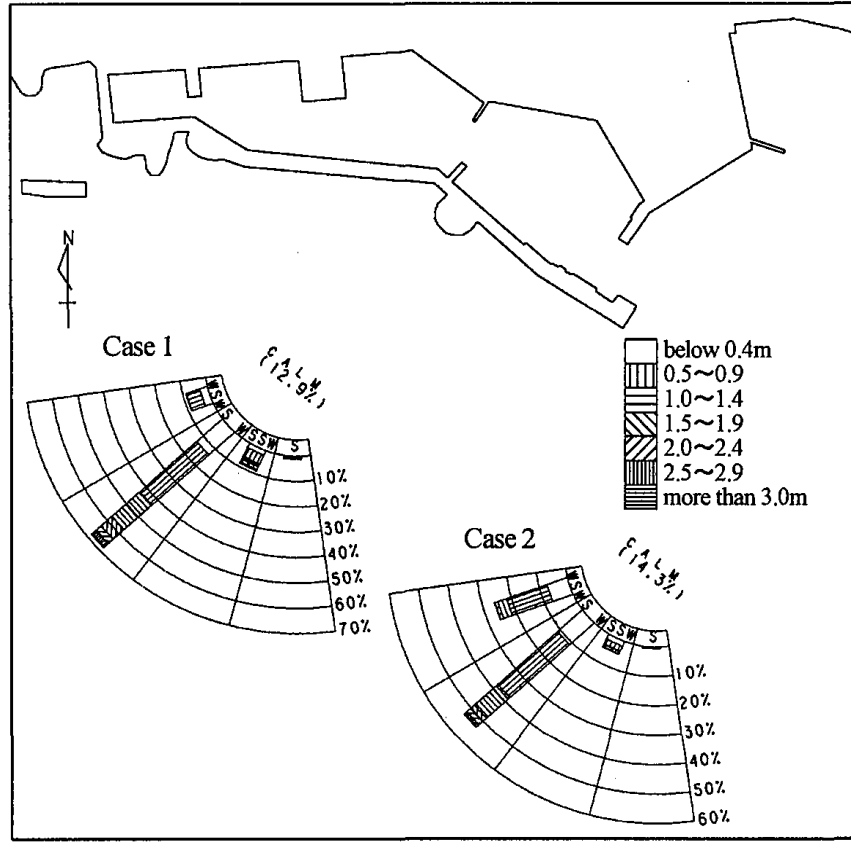

Fig. 7 Frequency of wave appearance in wave direction and wave height

\subsection{Characteristics of incoming Waves}

To understand the characteristics of the incoming waves at Kumaishi Fishing Port, The observation data collected at ST.1, outside the port, in Cases 1 and 2, were analyzed to determine the frequencies of the incoming waves and the energy of the long-period components. The data were obtained 813 times in Case 1 and 1,746 times in Case 2.

Fig. 7 shows the frequencies of wave appearances in incoming wave direction and wave height with $H_{1 / 3}$ which is defined by the zero-up crossing method. During the observation periods, the incoming waves in the SW direction were dominant in the fishing port and accounted for more than $60 \%$ of the total incoming waves. More than $70 \%$ of the waves were lower than $1.0 \mathrm{~m}$. The appearance rates of $2.0 \mathrm{~m}$ or higher waves under stormy

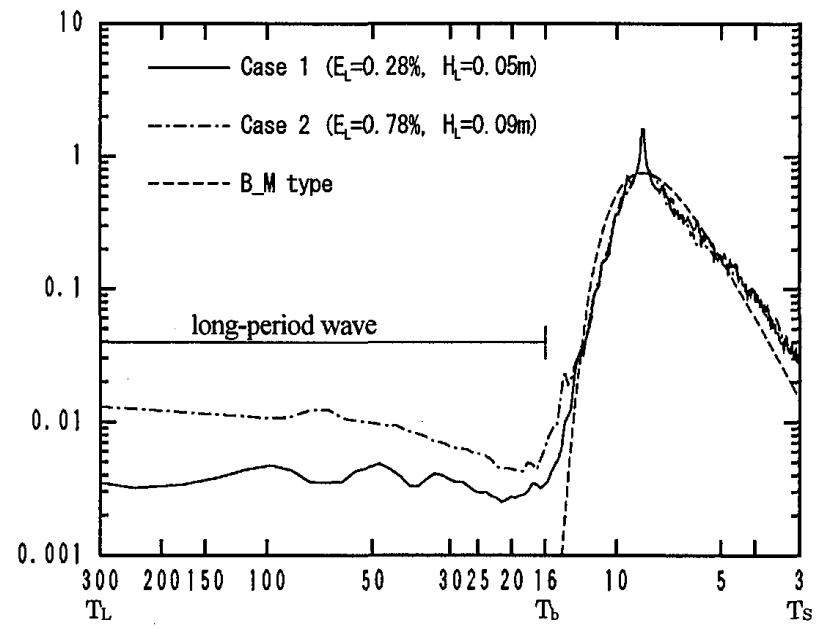

Fig. 8 Observational wave spectra

weather conditions are $5.7 \%(\mathrm{~N}=47$ times $)$ in Case 1 and $4.1 \%(\mathrm{~N}=72$ times $)$ in Case 2.

Figure 8 shows the observational waves spectra, normalized as proposed by the authors, under the stormy weather with waves which are approximately $2.0 \mathrm{~m}$ or higher. In the figure, $\mathrm{E}_{\mathrm{L}}$ represents the energy duty factor of long-period waves and $\mathrm{H}_{\mathrm{L}}$ represents the height of the long-period waves corresponding to the significant wave height $\mathrm{H}_{1 / 3}=1.0 \mathrm{~m}$. These values are calculated from Equations (1) through (3).

$$
\left.\begin{array}{l}
m_{0 S}=\int_{1 / T_{b}}^{1 / T_{S}} S(f) d f \\
m_{0 L}=\int_{1 / T_{L}}^{1 / T_{b}} S(f) d f \\
m_{0}=\int_{1 / T_{L}}^{1 / T_{S}} S(f) d f
\end{array}\right\}
$$


Where $S$ (f) represents the power spectrum, $T_{s}$ represents the lower-limit period on the short-period side, $\mathrm{T}_{\mathrm{L}}$ represents the upper-limit period on the long-period side, and $T_{b}$ represents the boundary period between short-period and long-period waves. Their values were set at $\mathrm{T}_{\mathrm{s}}=3.0 \mathrm{~s}, \mathrm{~T}_{\mathrm{L}}=300.0 \mathrm{~s}$, and $\mathrm{T}_{\mathrm{b}}=16.0 \mathrm{~s}$.

In Cases 1 and 2, the energy duty factor $E_{\mathrm{L}}$ is 0.28 to $0.76 \%$ and $\mathrm{H}_{\mathrm{L}}$ is 0.05 to $0.09 \mathrm{~m}$. The $\mathrm{E}_{\mathrm{L}}$ tends to be greater during the Case 2 period.

\subsection{Port Propagation Characteristics}

Incoming waves contain about $1.0 \%$ long-period components. The characteristics of long-period components are analyzed below.

Typical examples of stormy weather in Cases 1 and 2 are shown in Fig. 9 with the wave spectrum ST.1 (outside the port) and ST.2 (inside the port) at 15:00 $\left(\mathrm{H}_{1 / 3}=3.07 \mathrm{~m}\right.$ ) on January 22,2002 and at $0: 00\left(\mathrm{H}_{1 / 3}=4.16 \mathrm{~m}\right)$ on January 29,2003 . The period band corresponding to the significant wave period $\mathrm{T}_{1 / 3}$ peaks at ST.1 in this figure.

A long-period band, the period which is 16.0 seconds or longer, has a gentle peak but its energy level is low. At ST.2, the energy of the period band for the significant wave period is reduced and that of a long period band is amplified. In period bands, the long-period waves propagated into the port may resonate with natural periods of ports and their energy may be amplified.

If the port disturbances at Kumaishi Fishing Port are attributable to the resonances between the natural periods of the port and the long-period waves, a peak period of the wave spectrum in the port under the stormy weather may always be found in a similar period band. As shown in Fig.10, the energy indicates a tendency of selective amplifications in a similar period band. Therefore, port disturbances can be assumed as resonances in stationary states.

To verify this assumption, the authors extracted the dominant period from the wave spectrum of the long-period band at ST.2 under the stormy weather using the Empirical Eigenfunction Method (EEM), a technique for analyzing main wave components. EEM is often employed to determine the orthogonal function empirically from measured data to approximate a function $^{(3)}$. If the wave spectrum $\mathrm{S}$ (f) is observed $t$ times as shown in Fig. 11, the spectral density $\mathrm{S}_{\mathrm{t}}(\mathrm{f})$ at a certain time can be represented as the sum of products

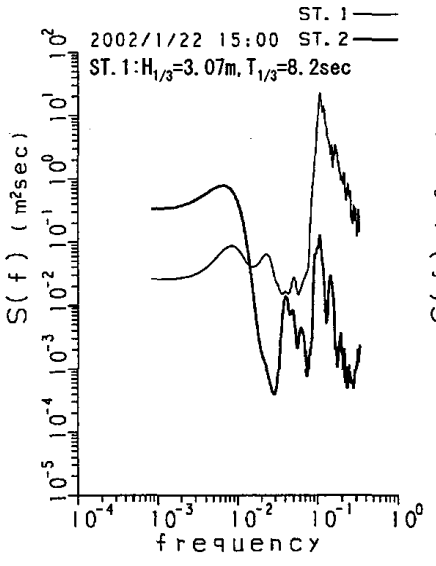

Case 1
Case 2

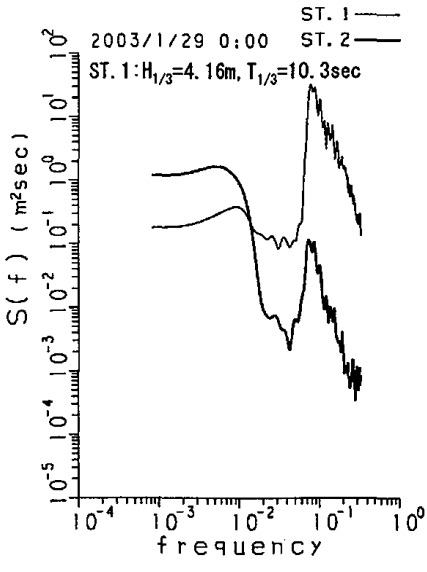

Fig. 9 Comparison of wave spectra

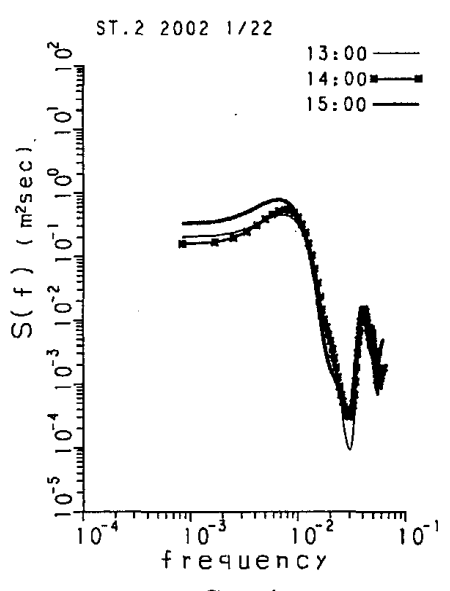

Case 1

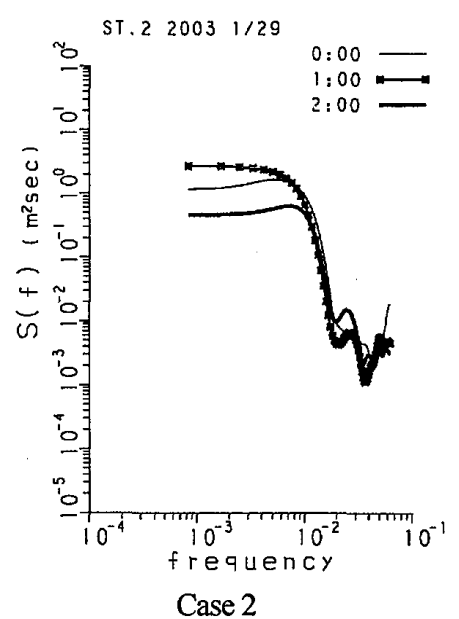

Case 2
Fig. 10 Comparison of wave spectra

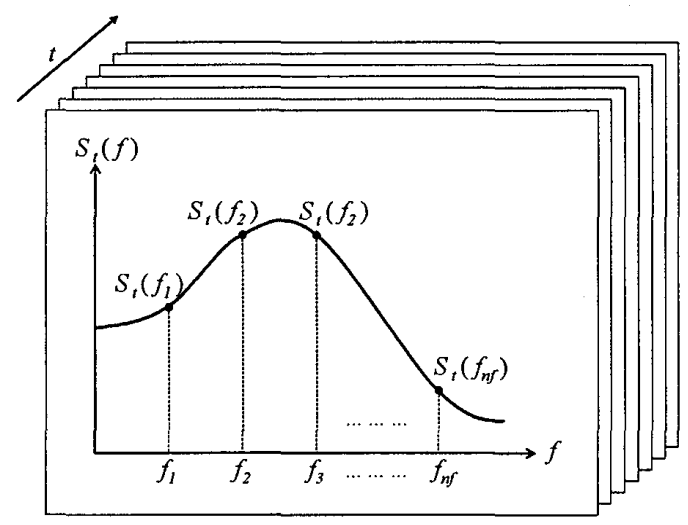

Fig. 11 Conceptual diagram of empirical eigenfunction method

of the time function $c_{k}(t)$ and the spatial function $e_{k}(f)$ shown in Equation (4). If the time function $c_{k}(t)$ is defined as a weight factor and the spatial function $e_{k}(f)$ is defined as an orthogonal function, it is resolved into a problem of eigenvalue and Equation (5) is obtained. $\mathrm{V}$ is the covariance matrix given in Equation (6) and $\lambda$ is the eigenvalue of $\mathrm{V}$ which maximizes the dispersion here. 
The proportion of $\lambda_{\mathrm{n}}$ is obtained from Equation (7). The weight factor $c_{n}(t)$ is obtained from Equation (8) using the eigenvector $e_{n}(f)$ of $V$ corresponding to $\lambda_{n}$.

$$
\begin{aligned}
& S_{t}(f)=c_{1} e_{1}+c_{2} e_{2} \cdots c_{n} e_{n f}=\sum_{k}^{n} c_{k}(t) e_{k}(f) \cdots(4) \\
& V \vec{e}(f)=\lambda \cdot \vec{e}(f) \\
& V=\left[V_{i j}\right]=\frac{1}{n_{f} n_{t}} \sum_{t=1}^{n_{t}} S_{t}(i) \cdot S_{t}(j) \\
& \left.\begin{array}{l}
\text { proportion of } \lambda_{n}=\lambda_{n} / \sum_{k=1}^{n_{f}} \lambda_{k} \\
\sum_{k=1}^{n_{f}} \lambda_{k}=\frac{1}{n_{f} \cdot n_{t}} \sum_{i=1}^{n_{f}} \sum_{t=1}^{n_{t}} S_{t}(i)^{2}
\end{array}\right\} \\
& c_{n}(t)=\sum_{f=1}^{n_{f}} S_{t}(f) \cdot e_{n}(f)
\end{aligned}
$$

Figure 12 shows the results of the EEM analyses in Modes 1 through 3, the periods of 400 to $600,200,133$, and 100 seconds show characteristic peaks. The total proportion in Modes 1 through 3 is $87.8 \%$ in Case 1, and $83.5 \%$ in Case 2. At Kumaishi Fishing Port, the periods of these three modes may be dominant in the long-period oscillations.

The port amplitude the amplification factors in each period band, which are seen in the results above, are analyzed to clarify the dominant periods. The observed series waveforms were separated into six period bands,

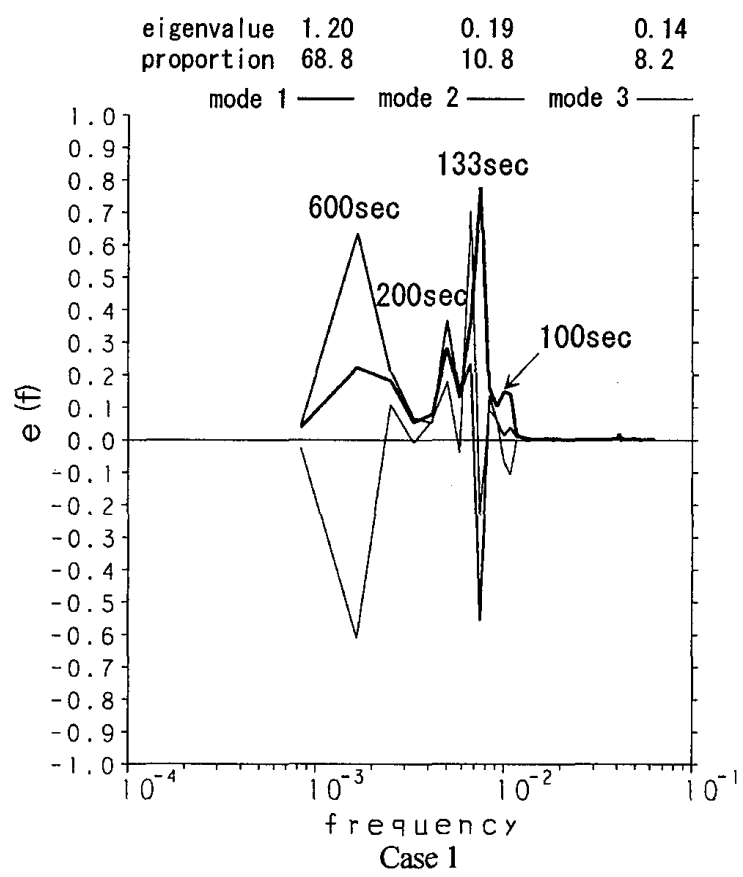

including the aforementioned dominant periods as shown in Fig. 13 and the significant wave heights $\mathrm{H}_{1 / 3}$ were calculated for each period band by Equations (9) through (10). These values were employed to calculate the amplitude amplification factors.

$$
\begin{aligned}
& H_{1 / 3}=4 \sqrt{m_{0}} \\
& m_{0}=\int_{1 / T_{2}}^{1 / T_{1}} S(f) d f
\end{aligned}
$$

The correlations between the wave height inside and outside the port were obtained by using the calculated significant wave height $\mathrm{H}_{1 / 3}$ at ST.1 and ST.2. Figure 14 shows the results of the correlation analyses and Table 3 lists the amplitude amplification factors obtained from the correlation equation. These results show a short-period band of 3 to 16 seconds is attenuated to 0.1 or less, and bands of 16 to 60 seconds are attenuated to about 0.2 to 0.4 . In contrast, bands of more than 60 seconds are amplified up to about 1.7 to 4.1 times.

In comparison of the amplitude amplification factors in Cases 1 and 2, those in Case2 are smaller than the ones in Case 1. This is attributed to the natural beach inside the port, and to the outgoing water passage in Case 2. The former is considered to have the effect of low reflection and the latter is considered to have the effect of dispersing the energy of long-period waves out of the port. The discrepancy in port boundary conditions may appear as the drop in the amplification factors.

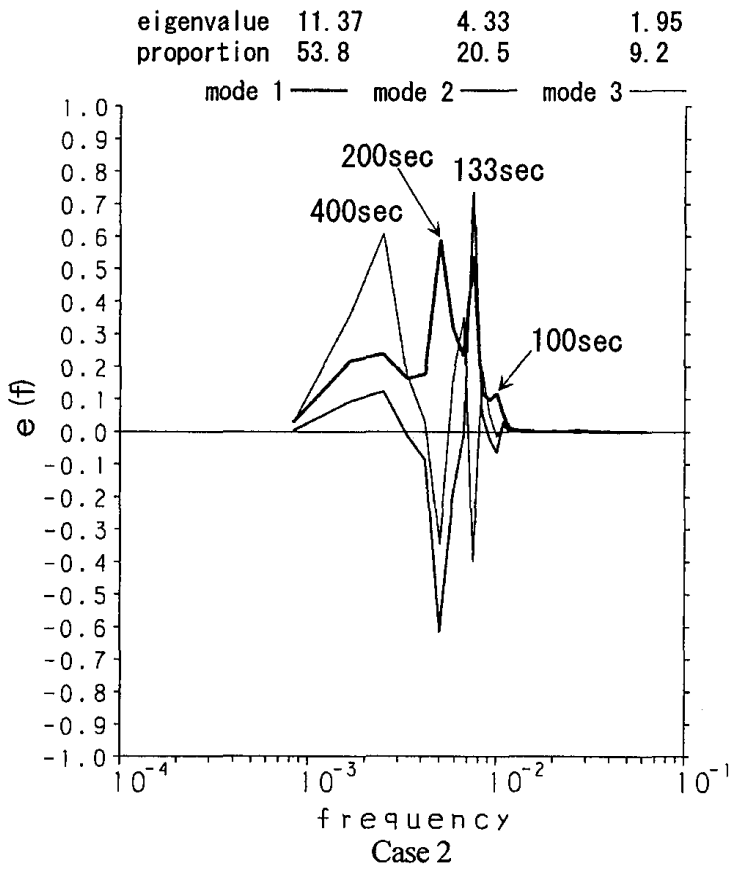

Fig. 12 Results of empirical eigenfunction method analysis 
Table 3 Rate of amplitude

\begin{tabular}{|c|c|c|}
\hline $\begin{array}{c}\text { Periodic belts } \\
(\mathrm{sec})\end{array}$ & Case 1 & Case 2 \\
\hline $240 \sim 600$ & 3.11 & 2.99 \\
\hline $150 \sim 240$ & 4.05 & 2.65 \\
\hline $60 \sim 150$ & 2.27 & 1.67 \\
\hline $30 \sim 60$ & 0.25 & 0.24 \\
\hline $16 \sim 30$ & 0.41 & 0.18 \\
\hline $3 \sim 16$ & 0.09 & 0.06 \\
\hline
\end{tabular}

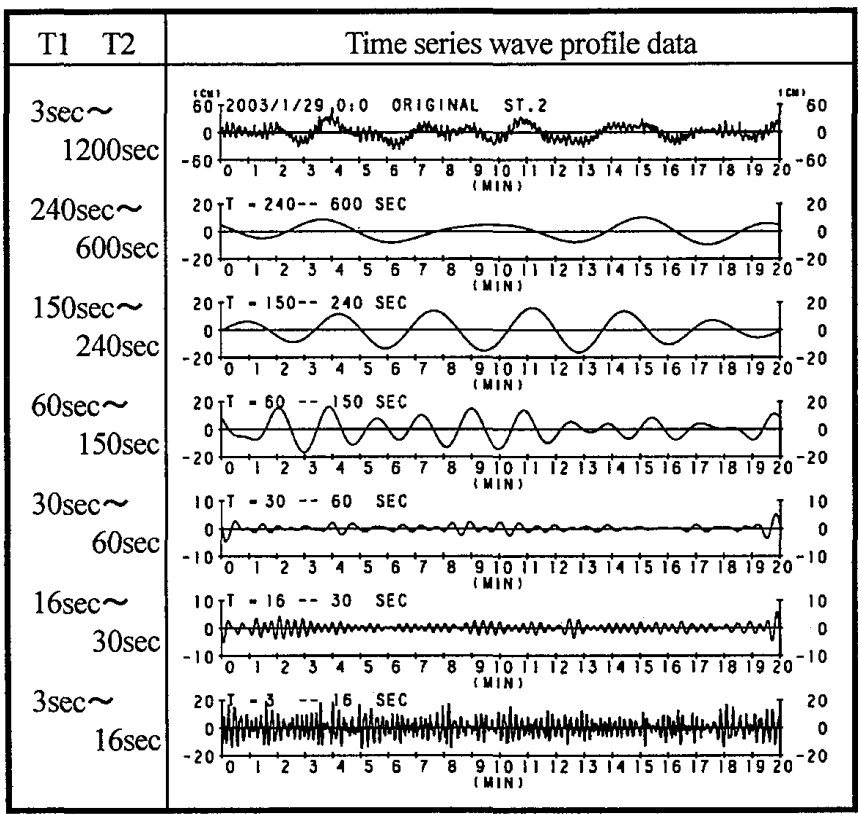

Fig. 13 Time series wave profile data for each periodic belt

\section{Numerical Analyses of Port Disturbance Factors}

\subsection{Natural Resonant Mode}

Numerical analyses of field observation data showed that long-period oscillations occur in several characteristic period bands under stormy weather conditions. If these characteristic period bands correspond to the natural periods which are dependent on the shape of Kumaishi Fishing Port, the port disturbances may be highly attributable to the long-period oscillations.

Natural periods were calculated by using the finite element method to verify these assumptions. The basic equation is the two-dimensional Berkhoff equation (hereinafter, mild slope equation) shown in Equation (11), which permits mild changes in water depth ${ }^{(6)}$. As Equation (12) shows, it is the stiffness matrix of elements. The equations (13) through (15) were converted into an eigenvalue calculation to acquire the eigenvalue $\lambda^{(7)(8)}$. The natural period in each mode was obtained by Equation (16) from the eigenvalue $\lambda$.

Figure 15 shows the results of a natural resonant mode analysis. The natural periods in Basic mode to Mode 3 are ranged from about 400 to 100 seconds.
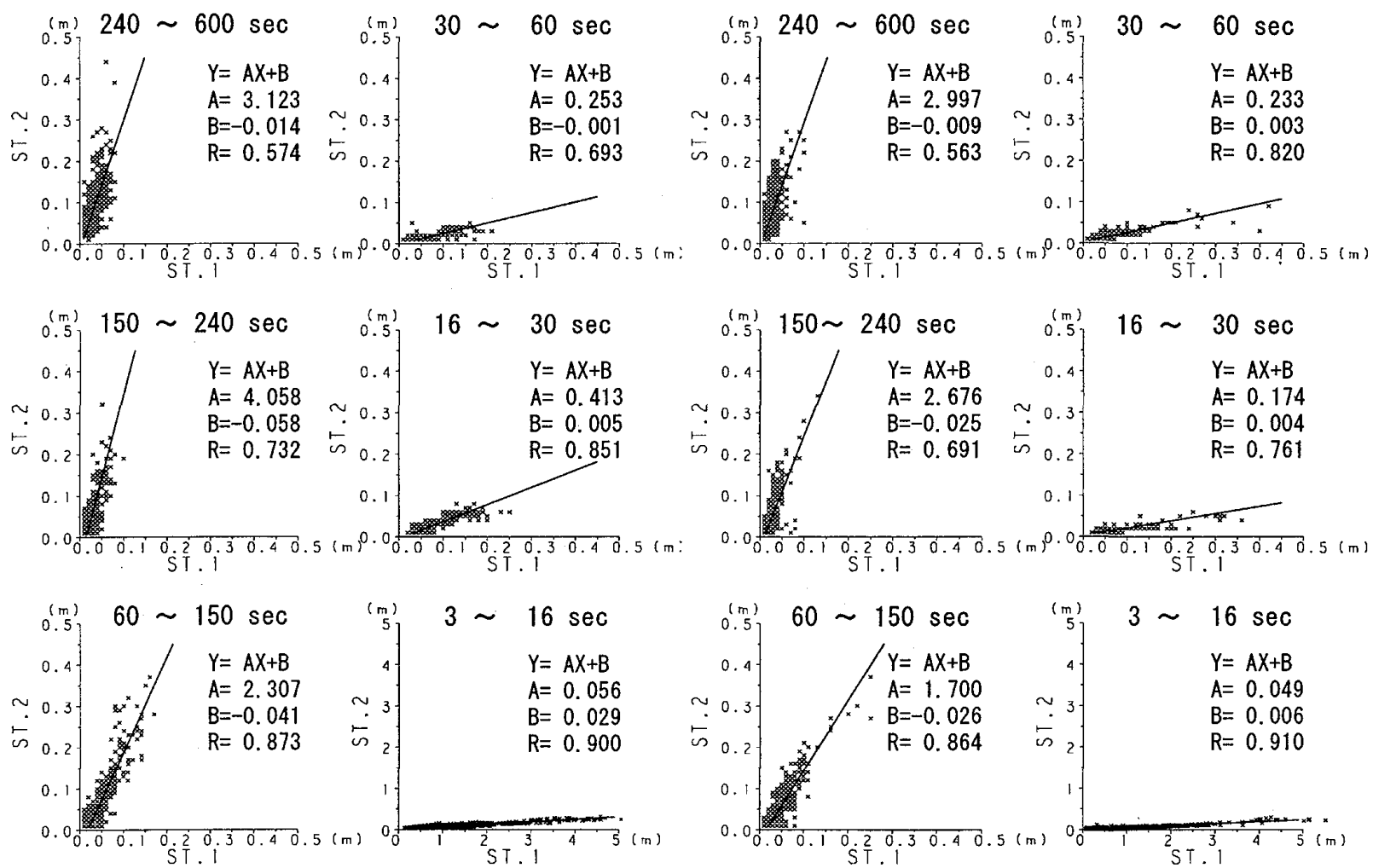

Case 1

Case 2

Fig. 14 Results of correlation analysis 


$$
\operatorname{div}(C \cdot C g \cdot \operatorname{grad} \Phi)+(C g / C) \omega^{2} \Phi=0
$$

where, $\Phi=\Phi(x, y)$ : potential of wave,

$C$ : wavevelocity, $C g$ : groupvelocity, $\omega:$ angular frequency of wave.

$K_{i j}^{e}=\int_{e} C \cdot C g \cdot \operatorname{grad} N_{i} d s \quad \int_{e} \omega^{2}(C g / C) N_{i} \cdot N_{j} d s$

where, $K_{i j}^{e}$ : stiffnessmatrix

$A x=\lambda B x$

where, $A$ and $B$ : global coefficient matrix.

$A_{e}=\int_{e} C \cdot C g \cdot \operatorname{grad} N_{i} \cdot \operatorname{grad} N_{j} d s$

$B_{e}=\int_{e} C g / C \cdot N_{i} \cdot N_{j} d s$

where, $A_{e}$ and $B_{e}$ : element stiffness matrix, $\lambda$ : eiqenvalue $\left(=\omega^{2}\right), x$ : eigenvector.

$T_{n}=\frac{2 \pi}{\sqrt{\lambda_{n}}}$

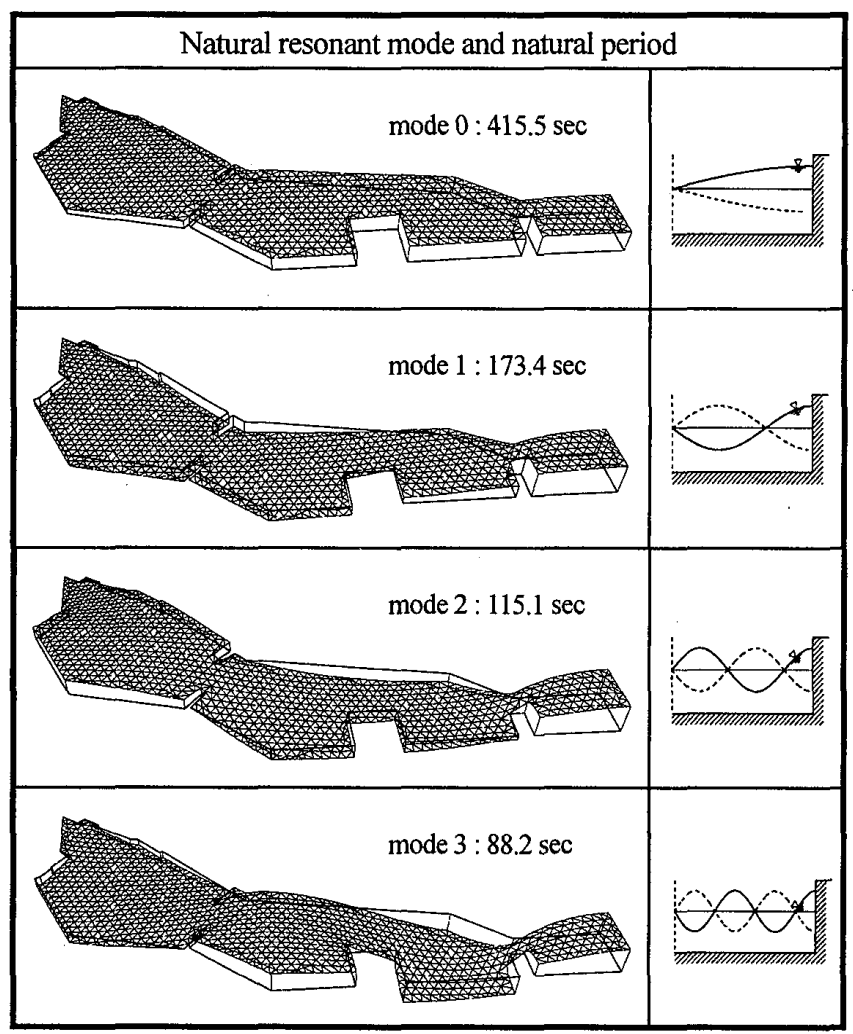

Fig. 15 Natural period of Kumaishi Fishing Port

Table 4 Numerical analysis conditions

\begin{tabular}{|c|c|c|}
\hline Wave direction & Wave spectrum & Periodic belts (sec) \\
\hline SSW & $\begin{array}{c}\text { Observational } \\
\text { wave spectrum } \\
\text { (Case 1) }\end{array}$ & $16.0 \sim 300.0$ \\
\hline
\end{tabular}

\subsection{Resonance Phenomenon}

The mild slope equation was solved as the basic equation by the finite element method to obtain the resonance period at Kumaishi Fishing Port. The analytical conditions are listed in Table 4. The representative wave direction was SSW, and the frequency spectrum was observational in the period of Case 1. The representative period band from 16 to 300 seconds was divided into 121 so that each wave height distribution was calculated. These divisions were linearly superimposed to acquire the resonance spectrum. Figure 16 shows the mesh for the calculation. The reflection coefficient was set at 0.98 for the upright quaywall, 0.4 for the wave-dissipating blocks, and 0.1 for the natural beach.

Figure 17 shows the resonance spectrum in deep in the port, which have often been stricken by disasters. The period bands of about 180,120 , and 90 seconds show the characteristic curves in these charts. In comparison of Cases 1 and 2, the amplification decrease in the period bands of about 180 and 90 seconds in Case 2 , where the port has the natural beach and the water passage. This probably occurs because the natural beach reduces reflections and the water passage disperses the energy of long-period waves out of the port.

\section{Discussion of Port Disturbance Factors}

\subsection{Collation of Real Phenomena and Numerical Analyses Results}

The results of analyzing the real phenomena with the field observation data and the natural and the resonance periods obtained from the numerical analyses are compared in Table 5. The data in this table attribute port disturbances to long-period oscillations resonance phenomena corresponding to the natural periods experienced in this port during Modes 1 through 3.

Table 5 Results of observations and numerical analyses

\begin{tabular}{|c|c|c|c|c|c|c|}
\hline \multicolumn{4}{|c|}{ Results of observation } & \multicolumn{3}{|c|}{ Results of numerical analysis } \\
\hline \multirow{3}{*}{$\begin{array}{c}\text { EEM } \\
\text { (peak period:sec) }\end{array}$} & \multicolumn{3}{|c|}{ Correlation analysis } & \multirow{3}{*}{ Mode } & \multirow{3}{*}{$\begin{array}{l}\text { Natural } \\
\text { period } \\
\text { (sec) }\end{array}$} & \multirow{3}{*}{$\begin{array}{l}\text { Resonance } \\
\text { spectrum } \\
\text { (peak period:sec) }\end{array}$} \\
\hline & \multirow{2}{*}{$\begin{array}{c}\text { Periodic } \\
\text { belts } \\
\text { (sec) }\end{array}$} & \multicolumn{2}{|c|}{$\begin{array}{c}\text { Rate of } \\
\text { amplitude }\end{array}$} & & & \\
\hline & & Case 1 & Case2 & & & \\
\hline 600,400 & $240 \sim 600$ & 3.11 & 2.99 & 0 & 415.5 & - \\
\hline 200 & $150 \sim 240$ & 4.05 & 2.65 & 1 & 173.4 & 188.5 \\
\hline 133 & \multirow{2}{*}{$60 \sim 150$} & \multirow{2}{*}{2.27} & \multirow{2}{*}{1.67} & 2 & 115.1 & 121.0 \\
\hline 100 & & & & 3 & 88.2 & 89.1 \\
\hline
\end{tabular}



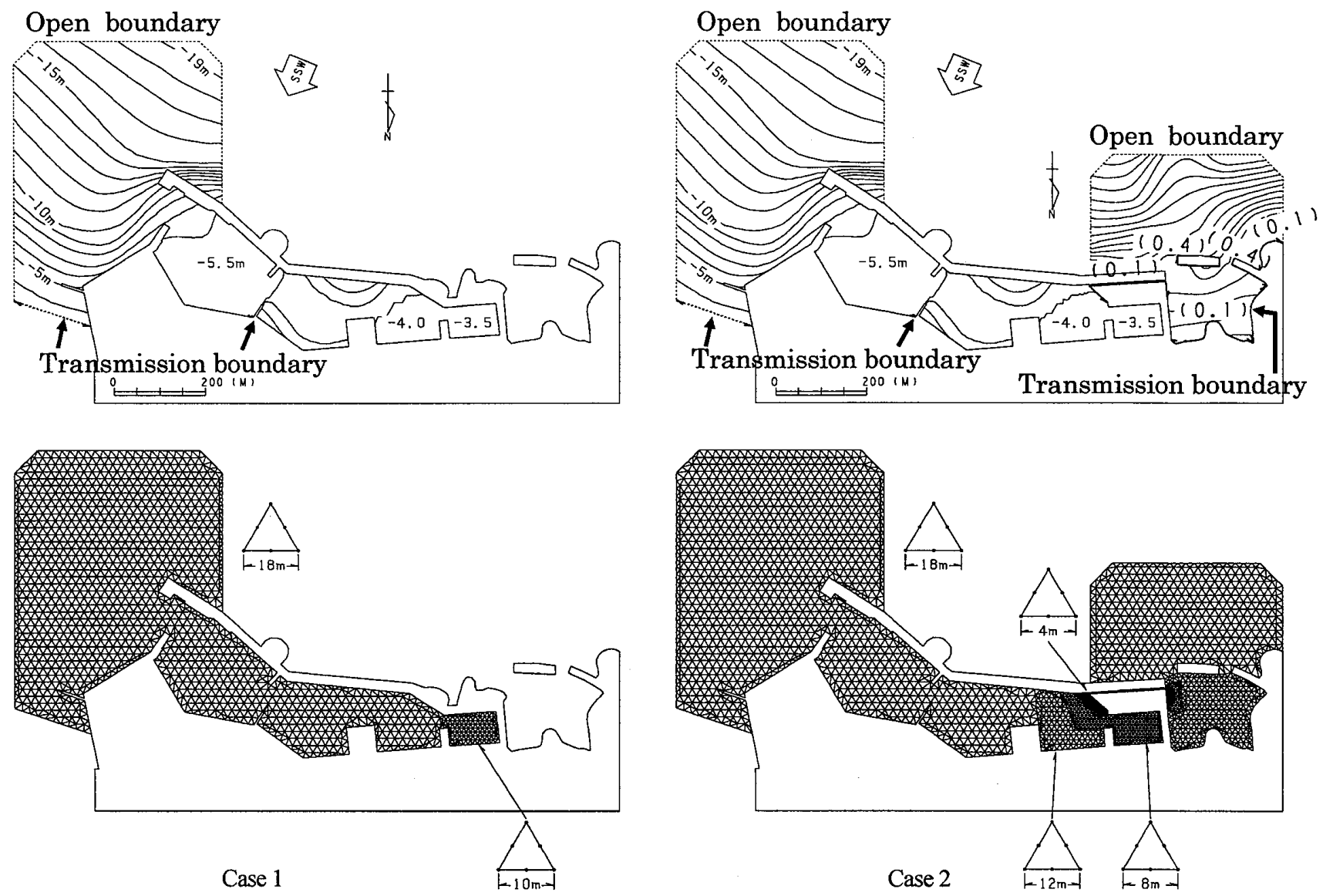

Fig. 16 Boundary condition and finite element mesh

$[A]$

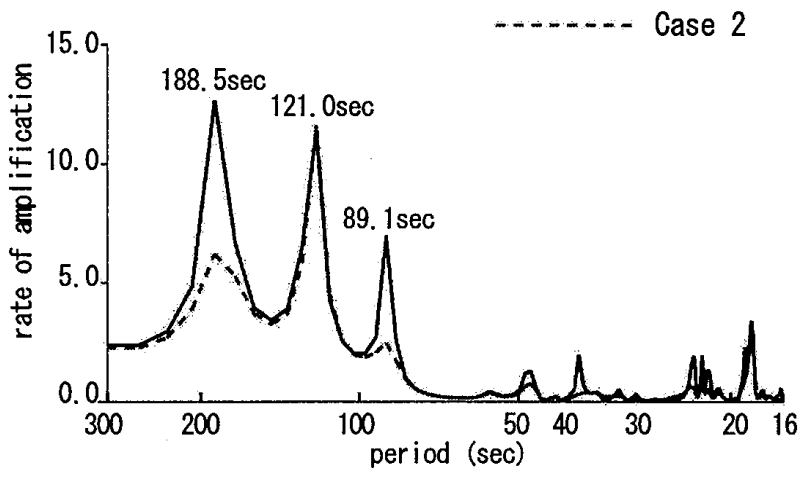

[B]

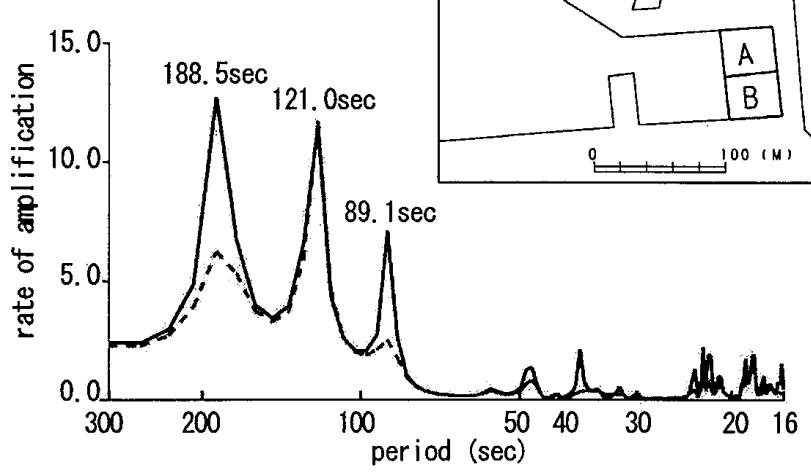

Fig. 17 Results of resonance spectrum analysis

\subsection{Proposal of Measures}

Technical guidelines for fishing ports mention the long-period oscillations accompanying the advance of long-period waves into ports can be reduced by: (1) installing offshore moles and breakwaters; (2) narrowing the port entrances; (3) installing jetties in the port; and, (4) preparing outlets for the water flowing into the ports.

In our present study, the water passage in Case 2 has the function (4) shown above. In addition, the natural beach in the port is expected to suppress the long-period oscillations. The above measures are also expected to produce secondary effects, such as reducing construction costs, and improvement on the quality of water in the port. Further study should be made to confirm if such measures produce effective suppressions of long-period oscillations.

\section{Conclusion}

In our present study, phenomena were analyzed by field observations and factors were analyzed numerically to clarify the mechanism of the port disturbance generation accompanying the advance of long-period waves into the port. These analyses clarified the following: 
(1) The numerical analyses of the factors of the port disturbances using field observation data show the port disturbances at Kumaishi Fishing Port could be attributed to the resonances between the natural periods of this port in Modes 1 through 3 and the long-period components of incoming waves.

(2) The results of the observations and the numerical analyses in this study show if a port has a natural beach and water passage, a resonance phenomenon reduces the amplitude amplification factor. Unlike other measures requiring facility constructions, these measures do not require high construction costs but produce secondary effects, such as improvement on the quality of water. These natural features are expected to suppress long-period oscillations.

(3) In the future, resonance periods, natural periods of fishing vessels and those related to the mooring at Kumaishi Fishing Port should be further analyzed to clarify the periods that cause disasters at moorings and to discuss measures of reduction rates of amplitude amplification factors occurring on these period bands.

\section{Acknowledgements}

The authors would like to thank members of Esashi Port Construction Office for providing the wave observational data, and Mr. T. Satoh of Kumashiro System Frontier Co., Ltd. for his comments on our numerical analyses.

\section{References}

(1) Noriyuki SATO and Hiroshi SAEKI : AN INVESTIGATION OF MOORD SHIPMOTIONS AT FISHING PORTS IN HOKKAIDO, Annual Journal of Civil Engineering in the Ocean, JSCE, vol.19, pp.637-642 (2003).

(2) Tetsuya HIRAISHI, Hideyosi FUJISAKU, Mitsutaka KONDOH, Tsuneo SATOH and Kouishi YAMAGUCHI : Observation of Long Period Waves in Kasima-Port, Annual journal of Civil Engineering in the Ocean, JSCE, vol.13, pp.141-146 (1997).

(3) Youichi ATSUMI, Yoshiki WAKAYAMA, Atushi KUNITA, Shin-Ichirou SEKIGUCHI, Katsutoshi KIMURA, Tsutomu KAWAGUCHI and Tethuya HIRAISHI : Characteristics of Long Period Waves by Field Observation and Statistical Analysis of It's Propagation in Harbour, Annual journal of Civil Engineering in the Ocean, JSCE, vol.13, pp.147-152 (1997).

(4) Naoya ABESHIMA, Kiyoshi AMAGAI, Nobuo KIMURA, Hiroaki UEDA and Shigeyoshi KODAMA : Statistical Property of Long-Period Gravity Waves in Hokkaido Coast, The Journal of Japan Institute of Navigation, vol.107, pp75-83 (2003).

(5) Kazumasa KATOH Akira YOSHIMATHU : A New Method Three-Dimensional Empirical Eigenfunction Analysis for Contour Maps, Report of the Port and Harbour Research Institute, vol.23, No2, pp.28-46 (1984).

(6) Berkhoff, J. C. W.: Computation of Combined Refraction-Diffraction, Proc.13th Coastal Eng. Conf., ASCE, vol.1, pp.471-490 (1972).

(7) C. TAYLOR, B. S. PATIL, and O. C. ZIENKIEWICZ: Harbour Oscillation: A Numerical Treatment for Undamped Natural modes, Proc. Inst. Civ. Eng., vol.43, pp.55-141 (1969).

(8) P. L. ARLETT, A.K.BAHRANI, and O. C. ZIENKIEWICZ: Application of Finite Elements to the Solution of Helmholtz's Equation, Proc. I. E. E., vol.115, pp.964-1762 (1968).

\section{Questions and Answers}

Masayoshi KUBO (Kobe University of Mercantile Marine): I have one question in this study. Is 20 minutes long enough to observe long-period oscillations of long natural periods? Please tell me how long an observation period should be and relations between long-period oscillations and long natural periods.

Naoya ABESHIMA (Graduate School of Fisheries Sciences of Hokkaido University): Thank you for your question. The basic mode to mode 3 at Kumaishi Fishing Port is about from 400 to $90 \mathrm{sec}$ so it is one of the major dominant factors of the port disturbances. An observation period should be at least longer than 40 minutes or the observation should be done continuously to discuss the long-period oscillations caused by natural periods. The observation period in our present study is 20 minutes because of some limitations on the observations but it will be performed with longer periods in the future. 